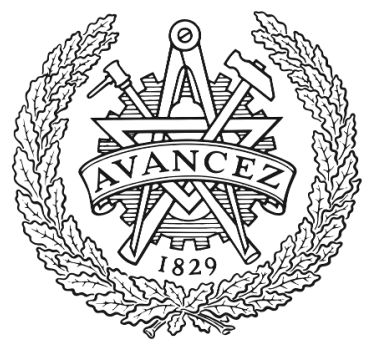

CHALMERS

UNIVERSITY OF TECHNOLOGY

\title{
New Understanding on Photocatalytic Mechanism of Nitrogen-Doped Graphene Quantum Dots-Decorated BiVO4 Nanojunction Photocatalysts
}

Downloaded from: https://research.chalmers.se, 2023-04-26 10:56 UTC

Citation for the original published paper (version of record):

Yang, H., Wang, P., Wang, D. et al (2017). New Understanding on Photocatalytic Mechanism of Nitrogen-Doped Graphene Quantum Dots-Decorated

BiVO4 Nanojunction Photocatalysts. ACS Omega, 2(7): 3766-3773.

http://dx.doi.org/10.1021/acsomega.7b00603

N.B. When citing this work, cite the original published paper. 


\section{New Understanding on Photocatalytic Mechanism of Nitrogen- Doped Graphene Quantum Dots-Decorated BiVO $_{4}$ Nanojunction Photocatalysts}

Hengyan Yang, ${ }^{\dagger, \|}$ Ping Wang, ${ }^{, \|, \dagger \odot}$ Ding Wang, ${ }^{\dagger}$ Yuankun Zhu, ${ }^{\dagger}$ Kunpeng Xie, ${ }^{\ddagger}$ Xianglong Zhao, ${ }^{*}, \S$ Junhe Yang, and Xianying Wang ${ }^{*} \dagger$

${ }^{\dagger}$ School of Materials Science and Technology, University of Shanghai for Science and Technology (USST), Jungong Road 516, 200093 Shanghai, P. R. China

${ }^{\ddagger}$ Chemical Engineering and Competence Centre for Catalysis, Chalmers University of Technology, Chalmersplatsen 4, 41296

Gothenburg, Sweden

${ }^{\S}$ Key Laboratory of Materials Physics and Anhui Key Laboratory of Nanomaterials and Nanostructures, Institute of Solid State Physics, Hefei Institutes of Physical Science, Chinese Academy of Sciences, P.O. Box 1125, 230031 Hefei, P. R. China

\section{Supporting Information}

ABSTRACT: Bismuth vanadate $\left(\mathrm{BiVO}_{4}\right)$ is a promising candidate as a visible-light-driven photocatalyst in the aspect of practical applications. To investigate the origin of active species from $\mathrm{BiVO}_{4}$ and understand the influence of the variations of the photocatalytic process, comparative studies on zero-dimensional nitrogen-doped graphene quantum dot (NGQD)-decorated $\mathrm{BiVO}_{4}$ have been carried out for methylene blue photodegradation. It was found that the hydroxyl group-rich NGQD surface and the established heterojunction structure between $\mathrm{NGQDs}$ and $\mathrm{BiVO}_{4}$ were greatly beneficial for the conversion of the ${ }^{\circ} \mathrm{OH}$ radical. With NGQD decoration, the dominant oxidant species for $\mathrm{NGQDs} / \mathrm{BiVO}_{4}$ were confirmed to be ${ }^{\bullet} \mathrm{OH}$ and $\mathrm{H}_{2} \mathrm{O}_{2}$, rather than holes originating from the valence band of unmodified $\mathrm{BiVO}_{4}$. The synergistic photocatalytic mechanism with respect to the interfacial charge transport and the conversion of active species was proposed. The achievement of the controllable active species significantly altering the activity may be applied for different photocatalytic reactions.

\section{INTRODUCTION}

Photocatalysis with semiconductor materials has attracted considerable interests in the past decades due to the potential applications in solar fuel production, environmental clean-up, water purification, etc. Among various semiconductor materials, bismuth vanadate $\left(\mathrm{BiVO}_{4}\right)$ mixed transition-metal oxide with a bandgap of $\sim 2.4 \mathrm{eV}$ has been recognized as one of the excellent visible-light-response photocatalysts. The material can be capable of harvesting up to $11 \%$ of the solar spectrum but also possesses a strong oxidation property with chemical/ photochemical stability. To date, it has been extensively used in various photocatalytic fields, such as elimination of organic pollutants $^{2,3}$ and photoelectrochemical tandem cell. ${ }^{4-6}$ However, unmodified $\mathrm{BiVO}_{4}$ usually shows low photocatalytic activity due to the high electron-hole recombination rate, poor charge transport, and slow surface reaction kinetics. ${ }^{7,8}$ To address the factors limiting the performance of $\mathrm{BiVO}_{4}$, the modification approaches have been demonstrated to be necessary, such as decomposition of electrocatalysts (noble metals, carbon materials, cobalt phosphate, layered double hydroxide, etc.), ${ }^{9-11}$ metal or nonmetal doping (W, Mo, C, P,

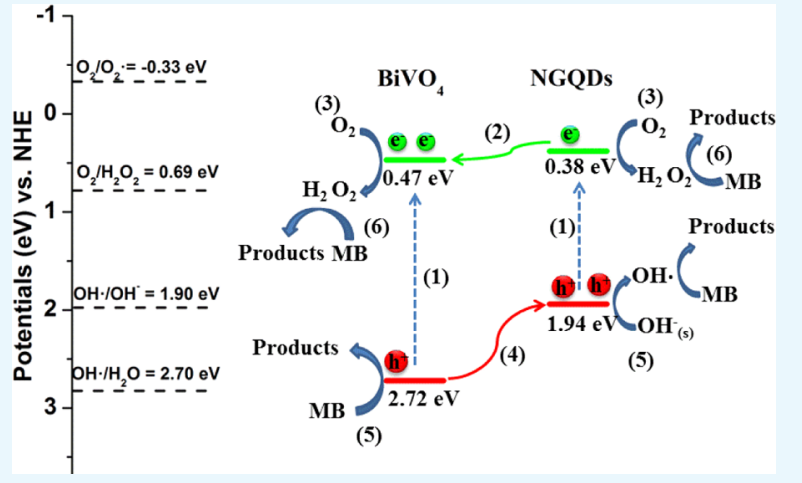

etc.), ${ }^{12-15}$ and combination with other semiconductors ( $\mathrm{Si}$, $\mathrm{WO}_{3}$, etc.). ${ }^{5,16}$ Yet, the surface chemistry of $\mathrm{BiVO}_{4}$ has not been well described and the generation of the active species during photocatalytic processes is still in debate in the literature. ${ }^{17-19}$

Inspired by recent significant advancements in the synthesis of zero-dimensional graphene quantum dots (GQDs) associated with the remarkable quantum-confinement and edge effects, ${ }^{20,21}$ GQDs have been used as a new type of electronacceptor material for photocatalysis and solar cell applications. $^{22-24}$ More interestingly, through atomic-scale tailoring, nitrogen-doped GQDs (NGQDs) could drastically alter their electronic characteristics and offer more active sites, thereby producing new phenomena and unusual properties. ${ }^{25,26}$ On the basis of the aforementioned argument on $\mathrm{BiVO}_{4}$, it is highly desirable for the construction of the NGQD-decorated $\mathrm{BiVO}_{4}$ to clarify the origin of active species on unmodified $\mathrm{BiVO}_{4}$ and

Received: May 15, 2017

Accepted: July 7, 2017

Published: July 19, 2017 


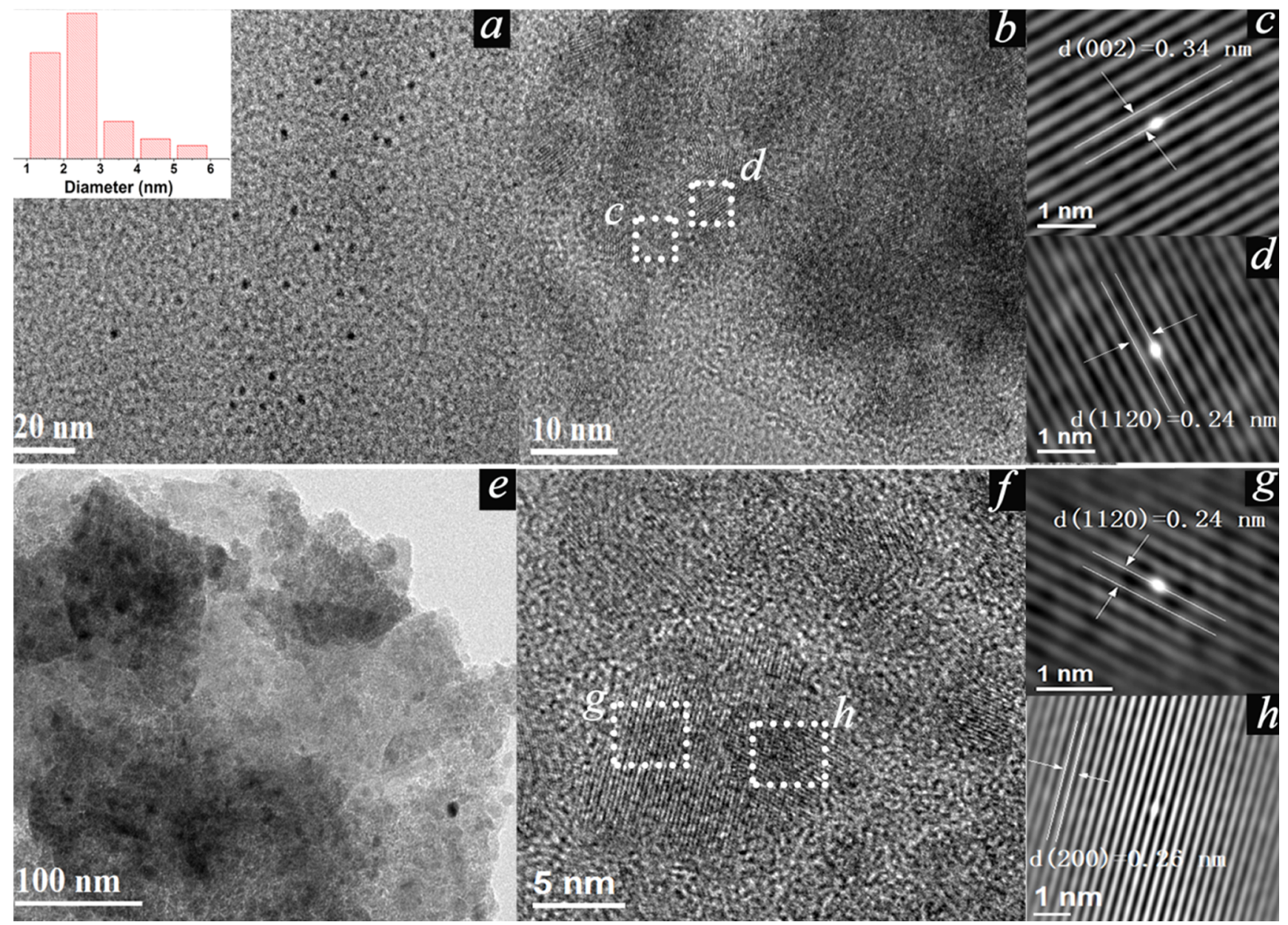

Figure 1. Representative TEM HRTEM and autocorrelated HRTEM lattice images of the pristine NGQDs (a-d) and 5 wt \% NGQDs/BiVO 4 (e$\mathrm{h}$ ). The inset in (a) is the corresponding size distribution of the pristine NGQDs. The autocorrelated HRTEM lattice images of the pristine NGQDs (c, d) are recorded from the corresponding selected areas in the HRTEM image (b). Autocorrelated HRTEM lattice images of the NGQDs (g) and $\mathrm{BiVO}_{4}(\mathrm{~h})$ in the composite are marked in the corresponding selected areas of the HRTEM image (f).

the effects of NGQDs. In particular, the variation of the generated active species during the photocatalytic process is almost unknown so far.

Herein, we report, for the first time, the facile preparation of the NGQDs $/ \mathrm{BiVO}_{4}$ nanojunction photocatalysts by an ultrasonic-assisted method, which allows the successful deposition and uniform dispersion of NGQDs on the surface of $\mathrm{BiVO}_{4}$ nanocrystals. Effects of NGQDs on the physicochemical property, optical property, electronic structure, and photocatalytic activity for the degradation of methylene blue (MB) were systematically studied. The surface effect of NGQDs, that is, the presence of plentiful hydroxyl groups, was found to be beneficial for the conversion of the ${ }^{\circ} \mathrm{OH}$ radical and the homogeneous dispersion on $\mathrm{BiVO}_{4}$. The estimation of the band positions of both NGQDs and $\mathrm{BiVO}_{4}$ revealed that the NGQDs acted as a junction component in the established heterojunction structure with $\mathrm{BiVO}_{4}$. Furthermore, the formation of $\mathrm{H}_{2} \mathrm{O}_{2}$ and ${ }^{\circ} \mathrm{OH}$ active species was probed, and the synergistic photocatalytic mechanism of $\mathrm{NGQDs} / \mathrm{BiVO}_{4}$ related to the interfacial charge transport and variation of active species during the photocatalytic process was also discussed in detail.

\section{RESULTS AND DISCUSSION}

Figure 1 shows representative transmission electron microscopy (TEM), high-resolution transmission electron microscopy (HRTEM), and autocorrelated HRTEM lattice images of the pristine NGQDs (Figure $1 \mathrm{a}-\mathrm{d}$ ) and 5 wt \% NGQDs $/ \mathrm{BiVO}_{4}$ (Figure $1 \mathrm{e}-\mathrm{h}$ ). Note that the autocorrelated HRTEM lattice images were recorded from the corresponding selected areas in the HRTEM image (marked by a white rectangle). Figure $1 \mathrm{a}, \mathrm{b}$ shows that the NGQDs have a uniform size ranging from 1.5 to $4 \mathrm{~nm}$ (inset of Figure 1a), with a small portion of aggregates of about $20 \mathrm{~nm}$. The lattice fringes of 0.34 and $0.24 \mathrm{~nm}$ correspond to the (002) and (1120) plane of the graphite form, respectively (Figure 1c,d). The TEM image of 5 wt \% NGQDs $/ \mathrm{BiVO}_{4}$ (Figure 1d) shows clear evidence for the deposition of NGQDs on the surface of $\mathrm{BiVO}_{4}$ nanoparticles. The HRTEM (Figure 1e) and the autocorrelated HRTEM lattice images (Figure $1 \mathrm{~g}-\mathrm{h}$ ) show the clear lattice fringes of 0.24 and $0.26 \mathrm{~nm}$, corresponding to the (1120) plane of NGQDs and (200) plane of $\mathrm{BiVO}_{4}$, respectively. The results unambiguously reveal the formation of an intimate contact between NGQDs and $\mathrm{BiVO}_{4}$ components in the composite.

Similar X-ray diffraction (XRD) patterns (Figure S1) were obtained for the pristine NGQDs, $\mathrm{BiVO}_{4}$, and NGQDdecorated $\mathrm{BiVO}_{4}$, indicating negligible change on the $\mathrm{BiVO}_{4}$ crystal structure by the introduction of NGQDs. The diffraction 

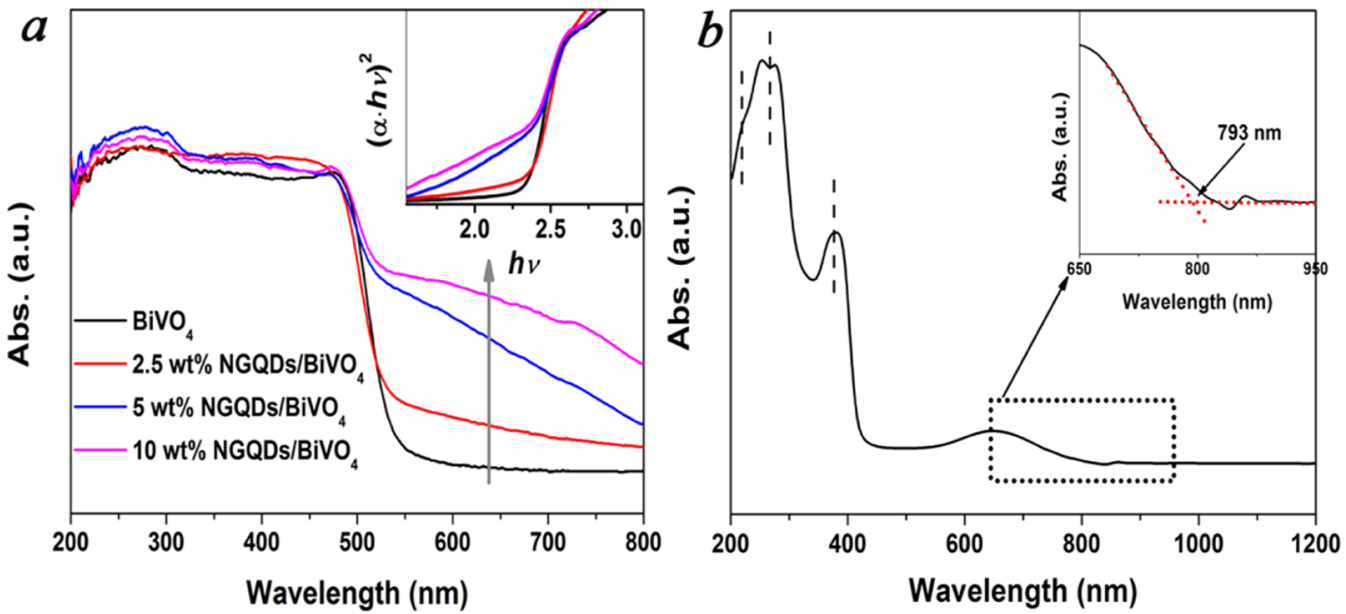

Figure 2. (a) Kubelka-Munk transformed UV-vis absorption spectra and Tauc plots (inset) of the as-synthesized samples. (b) UV-vis-NIR absorption spectrum of NGQDs (inset: the enlarged spectrum in the wavelength range of $650-950 \mathrm{~nm}$ ).

peaks of all samples can be ascribed to the monoclinic $\mathrm{BiVO}_{4}$ phase (JCPDS card 75-1867). As expected, no diffraction peaks of NGQDs were observed in the XRD patterns of NGQDs/ $\mathrm{BiVO}_{4}$ composites. This can be ascribed to the low loading and the high dispersion of NGQDs on the surface of $\mathrm{BiVO}_{4}$.

The Fourier transform infrared (FTIR) spectra of the pristine $\mathrm{NGQDs}, \mathrm{BiVO}_{4}$, and 5 wt \% $\mathrm{NGQDs} / \mathrm{BiVO}_{4}$ are shown in Figure S2. The spectrum of NGQDs shows that a broad absorption band at $3000-3500 \mathrm{~cm}^{-1}$ can be assigned to the stretching vibrations of $\mathrm{O}-\mathrm{H}$ and $\mathrm{N}-\mathrm{H}$, and the stretching vibration of $\mathrm{C}-\mathrm{H}$ is displayed at $\sim 2998 \mathrm{~cm}^{-1} \cdot{ }^{27,28}$ In the lowwavenumber region, two bands at 1667 and $1575 \mathrm{~cm}^{-1}$ are attributed to the vibrational absorption band of $\mathrm{C}-\mathrm{O}$ in $\mathrm{COOH}$ and $\mathrm{CONH}$ and the bending vibrations of $\mathrm{C}-\mathrm{C}$, respectively. ${ }^{29}$ For the pristine $\mathrm{BiVO}_{4}$, the strong absorption bands at $\sim 548$ and $735 \mathrm{~cm}^{-1}$ are the characteristic bending vibration of the $\mathrm{Bi}-\mathrm{O}$ bands ${ }^{30,31}$ and asymmetric stretching vibration of $\mathrm{V}-\mathrm{O}$ bands. ${ }^{32}$ The results imply that there are plenty of hydroxyl and amino groups on the surface of NGQDs; in contrast, the hydroxyl groups are scarcely formed on $\mathrm{BiVO}_{4}$. The hydroxyl groups play an important role in the formation of ${ }^{\bullet} \mathrm{OH}$ during the photocatalytic process, as will be discussed in detail below. The FTIR spectrum of 5 wt \% NGQDs $/ \mathrm{BiVO}_{4}$ is similar to that of pristine $\mathrm{BiVO}_{4}$, and the characteristic peaks of NGQDs cannot be clearly observed, which is probably due to the overlap of the spectra.

The UV-vis absorption spectrum of the pristine $\mathrm{BiVO}_{4}$ (Figure 2a) shows an absorption edge at around $550 \mathrm{~nm}$, corresponding to the effective bandgap of $2.25 \mathrm{eV}$. Figure $2 \mathrm{~b}$ shows the UV-vis-NIR absorption spectrum of NGQDs. Apparently in the UV region, there are three absorption peaks located at approximately $218 \mathrm{~nm}(5.68 \mathrm{eV}), 269 \mathrm{~nm}(4.60 \mathrm{eV})$, and $378 \mathrm{~nm}(3.27 \mathrm{eV})$, corresponding to the $\pi-\pi^{*}$ transitions from of $\mathrm{C}=\mathrm{C}$ and $\mathrm{C}=\mathrm{N}$ and $\mathrm{n}-\pi^{*}$ transition of the $\mathrm{p}-\pi$ orbit between the aromatic nitrogen and the conjugate structure, respectively. As shown in the enlarged resultant spectrum of NGQDs in the wavelength range from 650 to $950 \mathrm{~nm}$ (inset of Figure $2 \mathrm{~b}$ ), the absorption threshold of $\sim 793 \mathrm{~nm}$ is clearly observed with a long tail absorption upon about $830 \mathrm{~nm}$. It may be ascribed to the sub-bandgap transitions associated with the surface functional groups of NGQDs. The behavior is in good accordance with the results previously reported on surfacemodified $\mathrm{TiO}_{2}{ }^{33,34}$ Therefore, the bandgap between the top of the valence and bottom of the conduction band characteristic of the NGQDs can be determined to be ca. $1.56 \mathrm{eV}$. Consistently, the photograph shows a blue-green color of the NGQDs solution (Figure S3). For the $\mathrm{NGQDs} / \mathrm{BiVO}_{4}$ composites, an increased light-absorption capability and extended absorption onset are clearly observed in the visible region, along with the increase of the NGQD content (Figure 2a). With the benefits of the optical properties of NGQDs, the enhanced light absorption can refer to the higher production of electron-hole pairs under the same light irradiation condition.

The optimization of NGQD loading was studied from 2.5 to 10 wt \% for photocatalytic degradation of MB. Figure 3 displays the NGQD dose-dependent variation trend of the MB absorption capacity in the dark and the photodegradation rate constants under visible light irradiation $(\lambda>420 \mathrm{~nm})$. The blank reaction without catalysts confirmed that the selfdegradation of $\mathrm{MB}$ was negligible. A very high absorption ability was observed for the pristine NGQDs in the dark, owing to its unique properties, that is, size effect, plenty of surface sites, etc. Under irradiation, it was found to be photoactive, but a poor photocatalytic activity was observed. It may be ascribed to the intrinsic property for photogenerated charge separation or the deactivation caused by the possible agglomeration of NGQDs. ${ }^{35}$ With increasing the loading content of NGQDs, the absorption capacities and degradation rates of the NGQDs/ $\mathrm{BiVO}_{4}$ composites were obviously increased and reached the optima at $5 \mathrm{wt} \%$ of NGQDs. Compared to that of the pristine $\mathrm{BiVO}_{4}\left(0.51 \% \mathrm{~min}^{-1}\right)$, nearly twofold enhancement in the photodegradation rate constant was achieved for the 5 wt \% NGQDs $/ \mathrm{BiVO}_{4}$ composite $\left(1.14 \% \mathrm{~min}^{-1}\right)$. However, a large dose usage of NGQDs led to a significant decrease of the absorption capacity and photocatalytic performance in the 10 wt $\%$ NGQDs $/ \mathrm{BiVO}_{4}$ composite. The results indicated that the rational proportion of $\mathrm{NGQDs} / \mathrm{BiVO}_{4}$ had a crucial impact on the improvement of the absorption capacity and degradation rate. Otherwise, the reduction of synergistic efficacy between NGQDs and $\mathrm{BiVO}_{4}$ and the deteriorative particle agglomeration occurred. ${ }^{36}$ Besides, the light-screening effect of NGQDs can also be considered to be the possible reason, which partially blocked the visible-light absorption of $\mathrm{BiVO}_{4} \cdot{ }^{37,38}$ Furthermore, the addition of $\mathrm{H}_{2} \mathrm{O}_{2}\left(10 \mathrm{mg} \mathrm{L} \mathrm{L}^{-1}\right)$ in a parallel reaction enhanced the $\mathrm{MB}$ degradation rate of $5 \mathrm{wt} \% \mathrm{NGQDs} / \mathrm{BiVO}_{4}$, suggesting the role of $\mathrm{H}_{2} \mathrm{O}_{2}$ as an effective active species in 


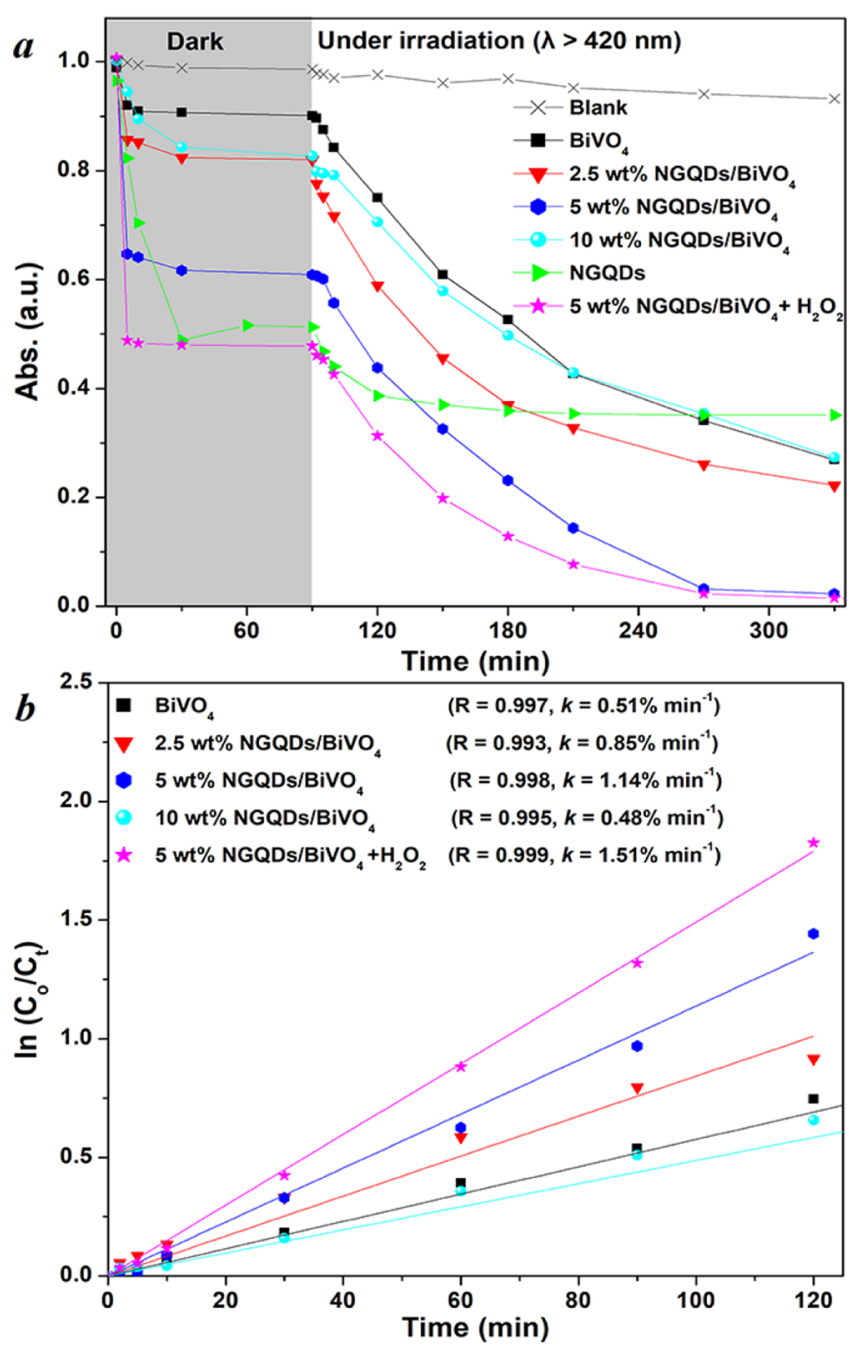

Figure 3. (a) $\mathrm{MB}$ absorption capacity in the dark and the photodegradation process under visible light irradiation $(\lambda>420$ $\mathrm{nm}$ ) over the as-synthesized samples. (b) Degradation rate constants of $\mathrm{MB}$ over the as-synthesized samples as fitted by using the first-order kinetics equation $\left(\ln \left(C_{0} / C_{t}\right)=k t\right)$.

scavenging the photogenerated electrons and accelerating the photo-oxidation process.

To further validate the synergistic effect of NGQDs, electrochemical impedance spectroscopy (EIS) and MottSchottky analysis measurements were conducted on the asprepared NGQDs/F-doped $\mathrm{SnO}_{2}$ (FTO) electrode, and the corresponding conduction band $\left(E_{\mathrm{CB}}\right)$ and valence band $\left(E_{\mathrm{VB}}\right)$ energy potentials can be estimated to be approximately $+0.38 \mathrm{~V}$ versus reversible hydrogen electrode $(\mathrm{RHE})$ and $+1.94 \mathrm{~V}$ versus RHE, respectively (Figure 4). In contrast, according to the Butler and Ginley method (detailed calculations given in Supporting Information), ${ }^{39}$ the positions of the $E_{\mathrm{CB}}$ and $E_{\mathrm{VB}}$ potentials of $\mathrm{BiVO}_{4}$ can be calculated to be about +0.47 and $+2.72 \mathrm{eV}$, respectively. The results reveal that the suitable band positions between NGQDs and $\mathrm{BiVO}_{4}$ would be favorable for the establishment of the heterojunction structure. The photoactive NGQDs acted as a junction component, which is different from the well-known function of GQDs as a sole electron acceptor (as will also be discussed in detail later). ${ }^{40}$

To gain more insight on the photocatalytic reaction process of the NGQD-decorated $\mathrm{BiVO}_{4}$, schematic illustration of the proposed photocatalytic mechanism related to the interfacial

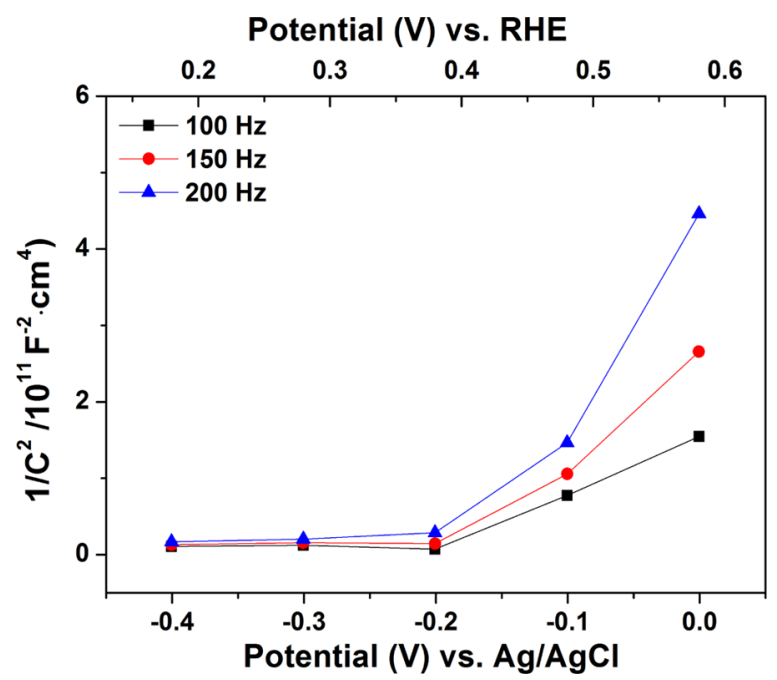

Figure 4. Mott-Schottky plots of NGQDs under dark conditions at various frequencies from 100 to $200 \mathrm{~Hz}$ with a three-electrode system in a $0.5 \mathrm{M} \mathrm{Na}_{2} \mathrm{SO}_{4}$ solution ( $\mathrm{pH} 6.5$ ).

charge transport and the generation of active species is shown in Figure 5a. The ${ }^{\circ} \mathrm{OH}$ trapping experiments by terephthalic acid (TA) photoluminescence (PL) probing were performed (Figure $5 \mathrm{~b}, \mathrm{c})$. Under visible-light irradiation $(\lambda>420 \mathrm{~nm}),(1)$ both $\mathrm{BiVO}_{4}$ and NGQDs can be excitated and simultaneously the holes $\left(\mathrm{h}^{+}\right)$and electrons $\left(\mathrm{e}^{-}\right)$were produced. (2) The photogenerated electrons on NGQDs can smoothly transfer to $\mathrm{BiVO}_{4}$ via the formed interfaces, due to the relatively low $E_{\mathrm{CB}}$ potential of $\mathrm{BiVO}_{4}$. (3) Because the $E_{\mathrm{CB}}$ potentials of NGQDs and $\mathrm{BiVO}_{4}$ are both located between the redox potential $\mathrm{O}_{2} /$ $\mathrm{O}_{2}{ }^{\bullet-}(-0.33 \mathrm{eV}$ vs normal hydrogen electrode (NHE)) and $\mathrm{O}_{2} / \mathrm{H}_{2} \mathrm{O}_{2} \quad(+0.69 \mathrm{eV}$ vs $\mathrm{NHE})$, the consumption of the electrons involving molecular oxygen may proceed via the two-electron reaction for the formation of $\mathrm{H}_{2} \mathrm{O}_{2}$, instead of $\mathrm{O}_{2}{ }^{\bullet-}$ via a single-electron reaction. (4) Simultaneously, the holes on the surface of $\mathrm{BiVO}_{4}$ can easily transfer to NGQDs via the interfaces, as the $E_{\mathrm{VB}}$ potential of NGQDs is much more negative than that of $\mathrm{BiVO}_{4}$. As a result, the built-in type II junction structure was formed between NGQDs and $\mathrm{BiVO}_{4}$. (5) In the case of $\mathrm{BiVO}_{4}$, the surface photogenerated holes were directly trapped to react with adsorbed MB species on the condition they did not recombine with electrons because no obvious PL signal of ${ }^{\circ} \mathrm{OH}$ was observed (Figure $5 b$ ). This indicated that the generation of ${ }^{\bullet} \mathrm{OH}$ was very scarce, which is in agreement with the reported results. ${ }^{18}$ The observation can be explained by two main reasons. First, the $E_{\mathrm{VB}}$ of $\mathrm{BiVO}_{4}$ $(+2.72 \mathrm{eV}$ vs NHE) is located too closely to the redox couples $\bullet \mathrm{OH} / \mathrm{H}_{2} \mathrm{O}(+2.7 \mathrm{eV}$ vs $\mathrm{NHE})$, and the generation of ${ }^{\bullet} \mathrm{OH}$ via $\cdot \mathrm{OH} / \mathrm{H}_{2} \mathrm{O}$ may be prohibited. Second, the lack of surfaceadsorbed $\mathrm{OH}$ groups $\left(\mathrm{OH}^{-}\right.$ads $)$on $\mathrm{BiVO}_{4}$ as demonstrated by FTIR spectra would dramatically limit the generation of ${ }^{\bullet} \mathrm{OH}$ via oxidation of $\mathrm{OH}^{-}$ads, even though the $E_{\mathrm{VB}}$ of $\mathrm{BiVO}_{4}$ is much more positive than the redox couples ${ }^{\circ} \mathrm{OH} / \mathrm{OH}^{-}(1.9 \mathrm{eV}$ vs $\mathrm{NHE}$ ). In contrast, the holes accumulated in the $E_{\mathrm{VB}}$ of NGQDs $(+1.94 \mathrm{~V})$ can react with the surface-adsorbed $\mathrm{OH}$ groups $\left(\mathrm{OH}^{-}\right.$ads $)$of NGQDs to generate a large amount of ${ }^{\bullet} \mathrm{OH}$, showing a strong PL signal of ${ }^{\bullet} \mathrm{OH}$ from the NGQDs/ $\mathrm{BiVO}_{4}$ (Figure 5c). We would like to note that the PL results also gave reliable evidence for the semiconducting characteristics of NGQDs with an opening bandgap, ${ }^{41,42}$ rather than an electron acceptor or ever sensitizer. The induced interfacial 

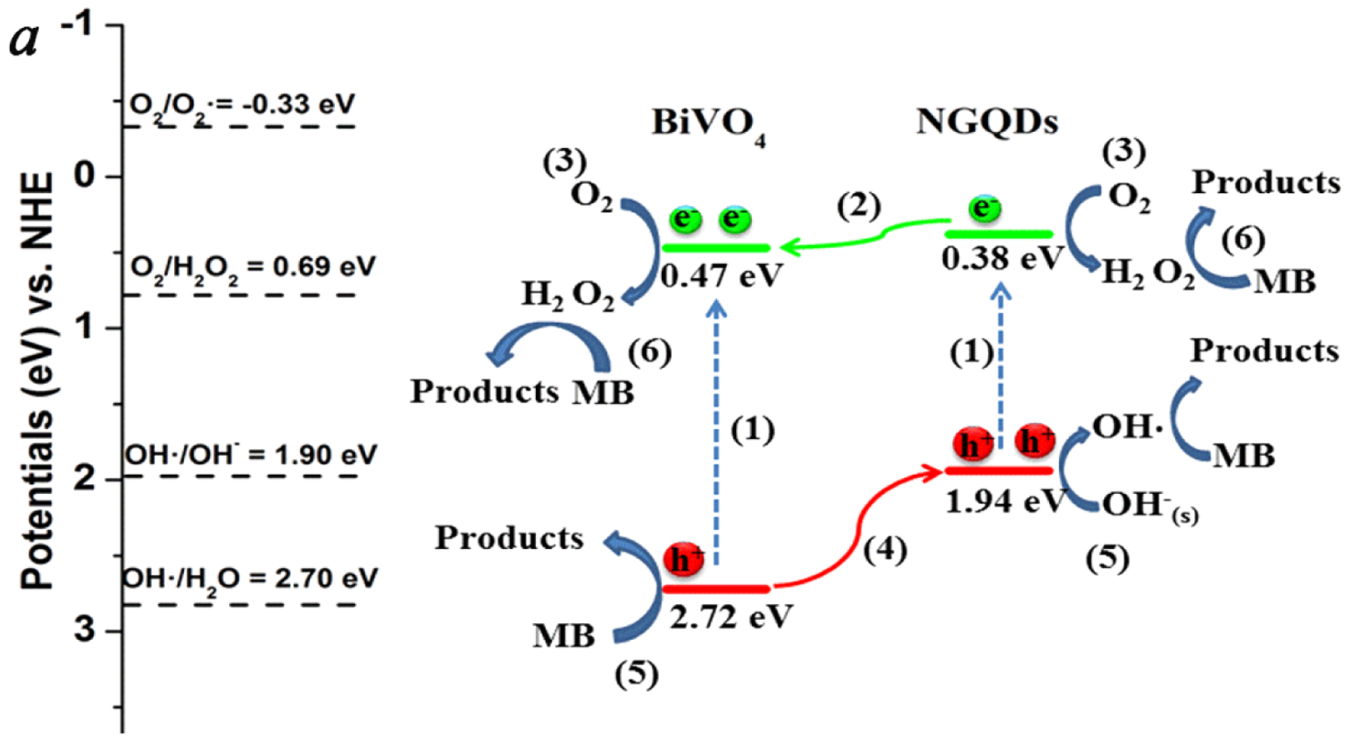

(5)
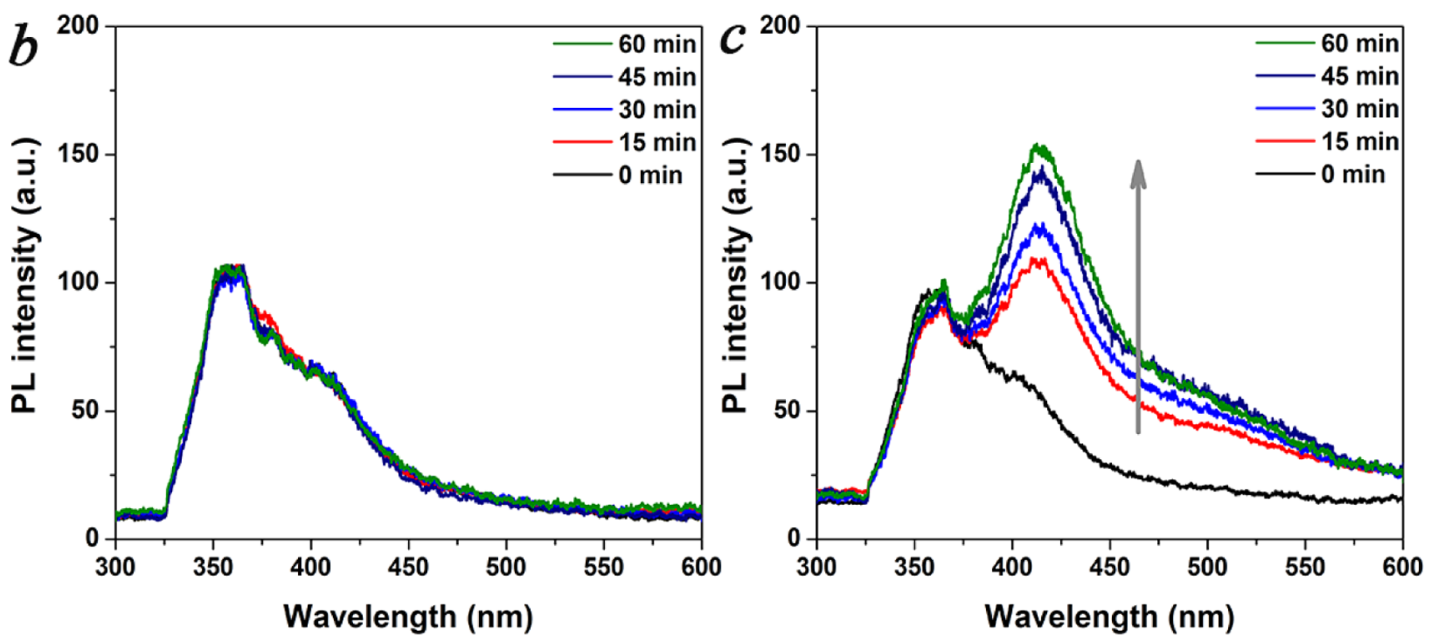

Figure 5. (a) Schematic illustration of the proposed photocatalytic mechanism and interfacial charge transport for the $\mathrm{NGQDs} / \mathrm{BiVO}_{4}$ nanojunction composite under visible-light irradiation $(\lambda>420 \mathrm{~nm}){ }^{\circ} \mathrm{OH}$ trapping $\mathrm{PL}$ spectra of $(\mathrm{b})$ the pristine $\mathrm{BiVO}_{4}$ and $(\mathrm{c}) 5 \mathrm{wt} \% \mathrm{NGQDs} / \mathrm{BiVO}_{4}$ samples by TA hydroxylation. The observed PL peak at about $360 \mathrm{~nm}$ originated from the sampling capillary glass tube. ${ }^{43}$

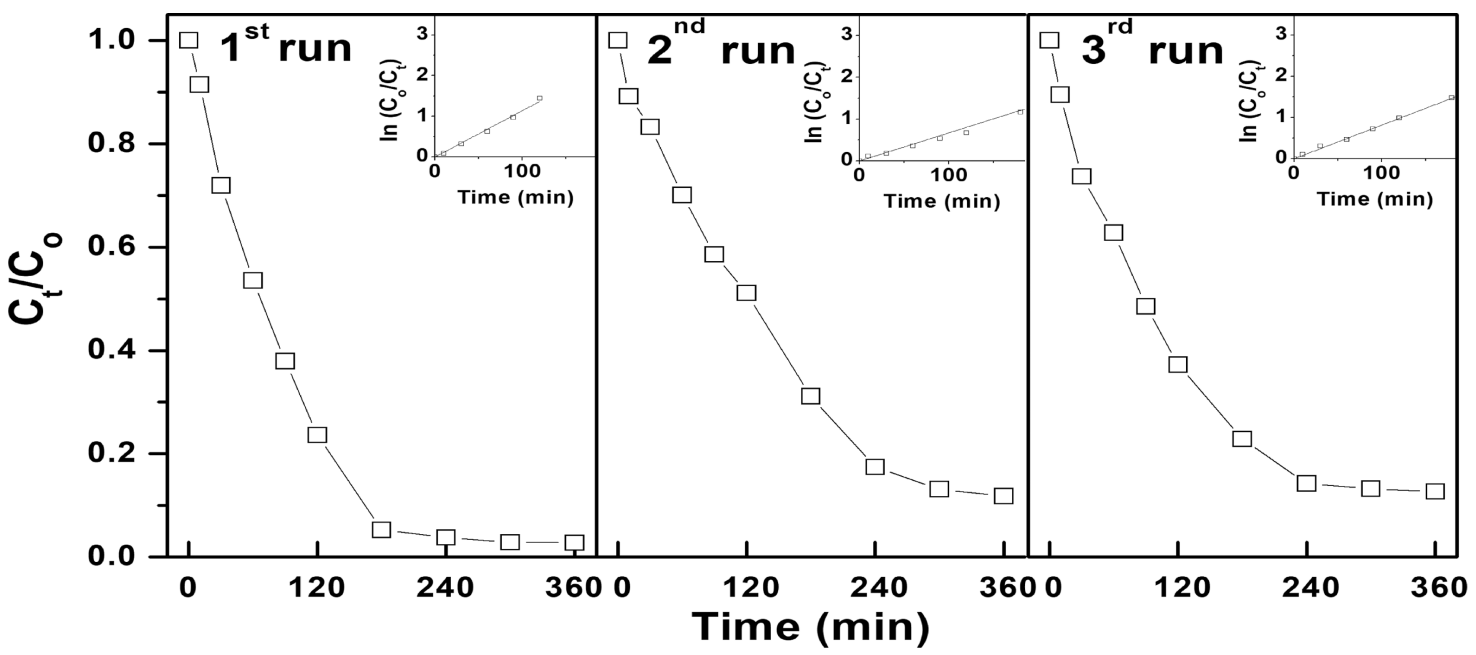

Figure 6. Recyclability of the $5 \mathrm{wt} \% \mathrm{NGQDs} / \mathrm{BiVO}_{4}$ nanocomposite for photodegradation of $\mathrm{MB}$. Insets: the corresponding first-order kinetic fitting curves.

hole transfer from $\mathrm{BiVO}_{4}$ to NGQDs promoted the generation of ${ }^{\bullet} \mathrm{OH}$ and greatly contributed to the enhancement of photocatalytic degradation rate. (6) Presumably owing to the excessive consumption of electrons for the formation of $\mathrm{H}_{2} \mathrm{O}_{2}$ 
via the two-electron reaction, no superfluous electrons can further react with $\mathrm{H}_{2} \mathrm{O}_{2}$ to form ${ }^{\bullet} \mathrm{OH} . \mathrm{H}_{2} \mathrm{O}_{2}$ as a characteristic of oxidative species would directly participate in the photocatalytic reaction. The decoration of a small amount of NGQDs not only increased the dye absorption capacity and visible-lightharvesting capacity but also facilitated the transfer and separation of photogenerated electron-hole pairs by aid of the built-in type II junction structure. Moreover, the results imply that the dominant oxidant species for NGQDs/ $/ \mathrm{BiVO}_{4}$ were converted to $\mathrm{H}_{2} \mathrm{O}_{2}$ and the ${ }^{\bullet} \mathrm{OH}$ radical rather than holes from the valence band of $\mathrm{BiVO}_{4}$. The formation of active species can be controlled during photocatalytic reactions, which may be useful for different photocatalytic applications.

The recyclability of the photocatalyst is an important parameter of the photocatalytic process for practical photocatalytic application. After each cycle, fresh MB solution was used for the next photocatalytic experiment, and taking into account the loss of the photocatalyst during the sampling process, the photocatalyst was collected from previous parallel experiments, followed by centrifugally washing and drying at 80 ${ }^{\circ} \mathrm{C}$ overnight. Figure 6 shows the recycling test of 5 wt \% $\mathrm{NGQDs} / \mathrm{BiVO}_{4}$ and the corresponding first-order kinetic fitting curves (insets). A slight decrease in the degradation rate was observed after being used repetitively for three cycles. It unveiled that the $\mathrm{NGQDs} / \mathrm{BiVO}_{4}$ nanocomposite was kept undamaged and the NGQDs remained tightly anchored on the surface of $\mathrm{BiVO}_{4}$. Therefore, the nanocomposite could be recognized as a stable photocatalyst, showing a good potential in the practical application for decomposing organic contaminant pollutants.

\section{CONCLUSIONS}

In summary, a novel $\mathrm{NGQDs} / \mathrm{BiVO}_{4}$ nanojunction photocatalyst was prepared by a simple method. The positive influence of NGQDs on the physicochemical, optical, and electrical properties of $\mathrm{NGQDs} / \mathrm{BiVO}_{4}$ has been demonstrated. The decoration of the optimum amount of 5 wt \% NGQDs on $\mathrm{BiVO}_{4}$ not only enhanced the absorption capacity and visiblelight-harvesting capacity but also facilitated the interfacial charge transport by aid of the built-in type II junction structure. More interestingly, the conversion of the dominant active species during the photocatalytic process can be achieved after the decoration of NGQDs. This study on the new understanding of the photocatalytic mechanism will provide insights into the design of new photocatalytic materials with a required electronic property. Note that by exploitation of a new synthetic approach and control of technical parameters, the development of high-quality NGQDs will be one of the major concerns in the ongoing and future work for extending the great potential in the photocatalysis field.

\section{EXPERIMENTAL SECTION}

Preparation of Photocatalysts. All reagents used in this study were used without further purification. According to the literature, ${ }^{23}$ the high-quality $\mathrm{BiVO}_{4}$ nanoparticles were synthesized in an acidic environment, ${ }^{44}$ where $\mathrm{BiVO}_{4}$ photocatalysts have been proven to be more active than those prepared under higher $\mathrm{pH}$ conditions. Typically, $10 \mathrm{mmol}$ of $\mathrm{Bi}\left(\mathrm{NO}_{3}\right)_{3} \cdot 5 \mathrm{H}_{2} \mathrm{O}$ (American Chemical Society (ACS) reagent, $\geq 98 \%$; Alfa Aesar) and $5 \mathrm{mmol}$ of $\mathrm{V}_{2} \mathrm{O}_{5}$ ( $\geq 99.6 \%$; Alfa Aesar) were mixed in $50 \mathrm{~mL}$ of $0.75 \mathrm{M} \mathrm{HNO}_{3}$ solution. The resulting yellow product was collected by filtration and dried at $80{ }^{\circ} \mathrm{C}$ overnight. The NGQDs were reproducibly prepared according to the one-pot hydrothermal method reported by Sun and coworkers: ${ }^{29} 0.63 \mathrm{~g}$ of anhydrous citric acid (ACS reagent, $\geq 99.5 \%$; Alfa Aesar) and $0.54 \mathrm{~g}$ of urea (ACS reagent, 99.0100.5\%; Alfa Aesar) were dissolved in $40 \mathrm{~mL}$ of water under stirring. The resulting solution was transferred into a $50 \mathrm{~mL}$ Teflon-lined stainless autoclave. The sealed autoclave was heated at $180^{\circ} \mathrm{C}$ for $6 \mathrm{~h}$ in an electric oven. The final product was centrifuged several times at $10000 \mathrm{rpm}$ for $10 \mathrm{~min}$. The obtained NGQD supernatants were redispersed in $30 \mathrm{~mL}$ of water for further use, and the concentration of the NGQD solution was calculated to be about $43 \mathrm{mg} \mathrm{mL}^{-1}$ from balance measurements after drying at $80{ }^{\circ} \mathrm{C}$ overnight. The ultrasonicassisted method was used for the preparation of NGQDs/ $\mathrm{BiVO}_{4}$ photocatalysts. Briefly, a desired weight ratio of NGQDs and $\mathrm{BiVO}_{4}$ was added into ethanol. The bottle was placed in an ultrasonic bath for $2 \mathrm{~h}$ and then vigorously stirred for another 2 h. After drying at $80{ }^{\circ} \mathrm{C}$ overnight, the resultant powders were directly heated at $180^{\circ} \mathrm{C}$ for $2 \mathrm{~h}$ in a tube oven under an argon atmosphere (quality 5.0).

Fabrication of NGQD Electrodes. The NGQDs/FTO electrodes were fabricated by the modified electrophoretic deposition (EPD) method. ${ }^{45}$ Typically, $10 \mathrm{~mL}$ of NGQDs suspension $\left(40 \mathrm{mg} \mathrm{mL}^{-1}\right)$ was prepared in $100 \mathrm{~mL}$ of isopropyl alcohol by sonication for $6 \mathrm{~h}$, followed by adding $0.005 \mathrm{~g}$ of $\mathrm{Mg}\left(\mathrm{NO}_{3}\right)_{2} \cdot 6 \mathrm{H}_{2} \mathrm{O}(\geq 98 \%$; Alfa Aesar) into the suspension with an ultrasonic dispersion for $1 \mathrm{~h}$. A clean FTO (as cathode) facing the stainless steel anode was immersed into this suspension. The distance between the two electrodes was fixed at about $5 \mathrm{~cm}$. The $\mathrm{Mg}^{2+}$-absorbed NGQD suspension was loaded in a quartz vessel as the electrolyte, and the electrophoresis process was performed at $50 \mathrm{~V}$ for $120 \mathrm{~s}$. After the EPD process, the prepared NGQDs/FTO electrodes were washed by ethanol and deionized water several times and dried in an argon stream at room temperature.

Characterization. The XRD patterns of all samples were recorded with a PANalytical MPD diffractometer using $\mathrm{Cu} \mathrm{K} \alpha$ radiation $(\lambda=0.1541 \mathrm{~nm})$, and the data were recorded from 10 to $70^{\circ}(2 \theta)$. Powder samples were examined by scanning electron microscopes using a LEO (Zeiss) 1530 Gemini fieldemission. TEM images were recorded by a Philips/FEI Tecnai F20 S-TWIN TEM instrument operating at $200 \mathrm{kV}$. The UVvis absorption spectra of the as-synthesized powdered samples were measured using $\mathrm{BaSO}_{4}$ as a reference on a Shimadzu UV2450 spectrophotometer. Bandgap energies were calculated by the analysis of the Tauc plots resulting from Kubelka-Munk transformation of the absorption spectra. The absorption spectrum of the NGQD solution was recorded by UV-visNIR spectroscopy (PerkinElmer LAMBDA 750) at room temperature. FTIR spectroscopy was performed on a PerkinElmer Spectrum 100 spectrometer using the typical potassium bromide $(\mathrm{KBr})$ pellet technique. The PL spectra were recorded at room temperature by using a HORIBA LabRam HR spectrometer with the $325 \mathrm{~nm}$ line of the $\mathrm{He}-\mathrm{Cd}$ laser as the excitation source.

Evaluation of Photocatalytic Activity. MB (Aladdin Chemical Reagent Corporation, Shanghai, China) was adopted as a hazardous organic pollutant. The evaluation of photocatalytic activity of the samples was performed on a home-built multizone photocatalytic reaction system, which consists of eight parallel windows and a $500 \mathrm{~W}$ midpressure $\mathrm{Hg}$ lamp ( $\mathrm{Hg}$ Arc lamp source; Shanghai Bilon Instrument Co., Ltd., Shanghai, P. R. China) equipped with a water filter and a 
$420 \mathrm{~nm}$ cutoff filter as a visible-light irradiation source. In a typical run, $10 \mathrm{mg}$ of catalysts was added into $50 \mathrm{~mL}$ of a 10.0 $\mathrm{mg} \mathrm{L}^{-1} \mathrm{MB}$ solution. Before irradiation, the suspension was magnetically stirred in the dark to ensure the adsorptiondesorption equilibrium of $\mathrm{MB}$ on the surface of the photocatalyst. Approximately $2 \mathrm{~mL}$ of the suspension was collected at certain time intervals and then centrifuged at 10 $000 \mathrm{rpm}$ for $10 \mathrm{~min}$. The concentration change of the $\mathrm{MB}$ solution was determined using a UV/vis spectrophotometer by monitoring its characteristic absorption peak at $665 \mathrm{~nm}$.

Detection of Hydroxyl Radicals $\left({ }^{\circ} \mathrm{OH}\right)$. Generation of - $\mathrm{OH}$ during the photocatalytic process was detected by the PL technique using TA as the probe molecule. TA can react with highly reactive ${ }^{\bullet} \mathrm{OH}$ to form highly fluorescent 2 -hydroxyterephthalic acid, which can be used to decompose, for example, organic pollutants. Experimental procedures were similar to the measurement of photodegradation, except that the MB solution was replaced by a freshly prepared mixed solution $(0.05 \mathrm{mM}$ TA and $0.2 \mathrm{mM} \mathrm{NaOH})$. Typically, the powder samples $(20$ $\mathrm{mg}$ ) were dispersed in the TA solution $(20 \mathrm{~mL})$ and when irradiated under visible light for a certain time interval, a negligible amount of the reaction solution was sampled by a capillary glass tube and measured on a HORIBA LabRam HR spectrometer with an excitation wavelength of $325 \mathrm{~nm}$.

Mott-Schottky Analysis. The EIS were measured by a potentiostat (Interface 1000 potentiostat; Gamry Instruments) with a three-electrode system in a $0.5 \mathrm{M} \mathrm{Na}_{2} \mathrm{SO}_{4}$ solution $(\mathrm{pH}$ 6.5). The potential was measured against an $\mathrm{Ag} / \mathrm{AgCl}$ reference and converted to NHE potentials by using $E(\mathrm{NHE})=E(\mathrm{Ag} /$ $\mathrm{AgCl})+0.197 \mathrm{~V}$. In the case of the Mott-Schottky analysis, it can be estimated from the intersection of a plot of $1 / C^{2}$ against $E$ by the following equation

$$
\frac{1}{C^{2}}=\frac{2}{e \epsilon \epsilon_{0} N}\left(E-E_{\mathrm{fb}}-\frac{k T}{e}\right)
$$

where $C$ is the space charge capacitance $\left(\mathrm{F} \mathrm{cm}^{-2}\right), e$ is the elementary charge $\left(1.62 \times 10^{-19} \mathrm{C}\right), \epsilon$ the relative dielectric constant of the semiconductor, $\epsilon_{0}$ is the permittivity of vacuum $\left(8.85 \times 10^{-12} \mathrm{~N}^{-1} \mathrm{C}^{2} \mathrm{~m}^{-2}\right), N$ is an acceptor density, $E$ is the applied potential $(\mathrm{V}), k$ is the Boltzmann constant $(1.38 \times$ $\left.10^{-23} \mathrm{~J} \mathrm{~K}^{-1}\right)$, and $T$ is the absolute temperature $(\mathrm{K})$.

\section{ASSOCIATED CONTENT}

\section{S Supporting Information}

The Supporting Information is available free of charge on the ACS Publications website at DOI: 10.1021/acsomega.7b00603.

Powder XRD patterns; FTIR spectra; photograph of NGQD solution; detailed calculation of band positions (PDF)

\section{AUTHOR INFORMATION}

\section{Corresponding Authors}

*E-mail: ping.wang@usst.edu.cn. Tel: +86-021-55270632 (P.W.).

*E-mail: xlzhao@issp.ac.cn (X.Z.).

*E-mail xianyingwang@usst.edu.cn (X.W.).

ORCID $\odot$

Ping Wang: 0000-0001-9023-7850

Author Contributions

${ }^{\|}$H.Y. and P.W. contributed equally to this work.

\section{Author Contributions}

The manuscript was written through contributions of all authors. All authors have given approval to the final version of the manuscript.

Notes

The authors declare no competing financial interest.

\section{ACKNOWLEDGMENTS}

We greatly appreciate the financial supports from the National Natural Science Foundation of China (Grant Numbers 51402193, 51572173, 51602197, and 11402149), Shanghai Municipal Science and Technology Commission (15520720300 and 16060502300), Shanghai Eastern Scholar Program (Grant Number QD2016014), and Shanghai Pujiang Talent Program (Grant Number 16PJ1407700).

\section{REFERENCES}

(1) Osterloh, F. E. Chem. Mater. 2008, 20, 35-54.

(2) Walsh, A.; Yan, Y.; Huda, M. N.; Aljassim, M. M.; Wei, S. H. Chem. Mater. 2009, 21, 547-551.

(3) Kim, J. H.; Jang, J. W.; Kang, H. J.; Magesh, G.; Kim, J. Y.; Kim, J. H.; Lee, J.; Lee, J. S. J. Catal. 2014, 317, 126-134.

(4) Zhong, M.; Hisatomi, T.; Kuang, Y.; Zhao, J.; Liu, M.; Iwase, A.; Jia, Q.; Nishiyama, H.; Minegishi, T.; Nakabayashi, M.; et al. J. Am. Chem. Soc. 2015, 137, 5053-60.

(5) Abdi, F. F.; Han, L.; Smets, A. H.; Zeman, M.; Dam, B.; van de Krol, R. Nat. Commun. 2013, 4, No. 2195.

(6) Kim, T. W.; Choi, K. S. Science 2014, 343, 990-994.

(7) Ma, Y.; Pendlebury, S. R.; Reynal, A.; Formal, F. L.; Durrant, J. R. Chem. Sci. 2014, 5, 2964-2973.

(8) Berglund, S. P.; Flaherty, D. W.; Hahn, N. T.; Bard, A. J.; Mullins, C. B. J. Phys. Chem. C 2011, 115, 3794-3802.

(9) Zhong, D. K.; Choi, S.; Gamelin, D. R. J. Am. Chem. Soc. 2011, 133, 18370-18377.

(10) He, W.; Wang, R.; Zhang, L.; Zhu, J.; Xiang, X.; Li, F. J. Mater. Chem. A 2015, 3, 17977-17982.

(11) Cao, S. W.; Yin, Z.; Barber, J.; Boey, F. Y.; Loo, S. C.; Xue, C. ACS Appl. Mater. Interfaces 2012, 4, 418-423.

(12) Park, H. S.; Kweon, K. E.; Ye, H.; Paek, E.; Hwang, G. S.; Bard, A. J. J. Phys. Chem. C 2011, 115, 17870-17879.

(13) Jo, W. J.; Jang, J.-W.; Kong, K.-J.; Kang, H. J.; Kim, J. Y.; Jun, H.; Parmar, K. P.; Lee, J. S. Angew. Chem., Int. Ed. 2012, 51, 3147-3151.

(14) Pilli, S. K.; Furtak, T. E.; Brown, L. D.; Deutsch, T. G.; Turner, J. A.; Herring, A. M. Energy Environ. Sci. 2011, 4, 5028-5034.

(15) Yin, C.; Zhu, S.; Chen, Z.; Zhang, W.; Gu, J.; Zhang, D. J. Mater. Chem. A 2013, 1, 8367-8378.

(16) Grigioni, I.; Stamplecoskie, K. G.; Selli, E.; Kamat, P. V. J. Phys. Chem. C 2015, 119, 20792-20800.

(17) Cheng, B.; Wang, W.; Shi, L.; Zhang, J.; Ran, J.; Yu, H. Int. J. Photoenergy 2012, 2012, No. 797968.

(18) Saison, T.; Chemin, N.; Chanéac, C.; Durupthy, O.; Mariey, L.; Maugé, F.; Brezová, V.; Jolivet, J. P. J. Phys. Chem. C 2015, 119, 12967-12977.

(19) Yuan, Q.; Lang, C.; Miao, X.; Jie, H.; Luo, S. L.; Au, C. T.; Yin, S. F. Chem. Eng. J. 2014, 255, 394-402.

(20) Mohanty, N.; Moore, D.; Xu, Z.; Sreeprasad, T. S.; Nagaraja, A.; Rodriguez, A. A.; Berry, V. Nat. Commun. 2012, 3, No. 844.

(21) Ritter, K. A.; Lyding, J. W. Nat. Mater. 2009, 8, 235-242.

(22) Li, Y.; Hu, Y.; Zhao, Y.; Shi, G.; Deng, L.; Hou, Y.; Qu, L. Adv. Mater. 2011, 23, 776-80.

(23) Gupta, B.; Kedawat, G.; Agrawal, Y.; Kumar, P.; Dwivedi, J.; Dhawan, S. K. RSC Adv. 2015, 5, 10623-10631.

(24) Zhu, Z.; Ma, J.; Wang, Z.; Mu, C.; Fan, Z.; Du, L.; Bai, Y.; Fan, L.; Yan, H.; Phillips, D. L.; Yang, S. J. Am. Chem. Soc. 2014, 136, 3760-3763.

(25) Yan, L.; Yang, Z.; Huhu, C.; Yue, H.; Gaoquan, S.; Liming, D.; Liangti, Q. J. Am. Chem. Soc. 2015, 134, 15-18. 
(26) Fei, H.; Ye, R.; Ye, G.; Gong, Y.; Peng, Z.; Fan, X.; Samuel, E. L.; Ajayan, P. M.; Tour, J. M. ACS Nano 2014, 8, 10837-10843.

(27) Kuo, N. J.; Chen, Y. S.; Wu, C. W.; Huang, C. Y.; Chan, Y. H.; Chen, I. W. Sci. Rep. 2016, 6, No. 30426.

(28) Finke, B.; Schröder, K.; Ohl, A. Plasma Processes Polym. 2009, 6, S70-S74.

(29) Qu, D.; Zheng, M.; Du, P.; Zhou, Y.; Zhang, L.; Li, D.; Tan, H.; Zhao, Z.; Xie, Z.; Sun, Z. Nanoscale 2013, 5, 12272-12277.

(30) Punia, R.; Kundu, R. S.; Hooda, J.; Dhankhar, S.; et al. J. Appl. Phys. 2011, 110, No. 033527.

(31) Bale, S.; Purnima, M.; Srinivasu, C.; Rahman, S. J. Alloys Compd. 2008, 457, 545-548.

(32) Pookmanee, P.; Kojinok, S.; Puntharod, R.; Sangsrichan, S.; Phanichphant, S. Ferroelectrics 2013, 456, 45-54.

(33) Ramakrishnan, A.; Neubert, S.; Mei, B.; Strunk, J.; Wang, L.; Bledowski, M.; Muhler, M.; Beranek, R. Chem. Commun. 2012, 48, 8556-8558.

(34) Wang, X.; Feng, Z.; Shi, J.; Jia, G.; Shen, S.; Zhou, J.; Li, C. Phys. Chem. Chem. Phys. 2010, 12, 7083-90.

(35) Li, Q.; Chen, B.; Xing, B. Environ. Sci. Technol. 2017, 51, 13641376.

(36) Marschall, R. Adv. Funct. Mater. 2014, 24, 2421-2440.

(37) Chen, P.; Wang, L.; Wang, P.; Kostka, A.; Wark, M.; Muhler, M.; Beranek, R. Catalysts 2015, 5, 270-285.

(38) Li, T.; He, Y.; Lin, H.; Cai, J.; Dong, L.; Wang, X.; Luo, M.; Zhao, L.; Yi, X.; Weng, W. Appl. Catal., B 2013, 138-139, 95-103.

(39) Butler, M. A.; Ginley, D. S. J. Electrochem. Soc. 1978, 125, 228232.

(40) Wan, X.; Long, G.; Huang, L.; Chen, Y. Adv. Mater. 2011, 23, 5342.

(41) Guo, B.; Liu, Q.; Chen, E.; Zhu, H.; Fang, L.; Gong, J. R. Nano Lett. 2010, 10, 4975.

(42) Yang, M.-L.; Zhang, N.; Lu, K.-Q.; Xu, Y.-J. Langmuir 2017, 33, 3161-3169.

(43) Zhu, Y.; Bu, X.; Wang, D.; Wang, P.; Chen, A.; Li, Q.; Yang, J.; Wang, X. RSC Adv. 2016, 6, 78846.

(44) Ng, Y. H.; Iwase, A.; Kudo, A.; Amal, R. J. Phys. Chem. Lett. 2010, 1, 2607-2612.

(45) Wu, Z. S.; Pei, S.; Ren, W.; Tang, D.; Gao, L.; Liu, B.; Li, F.; Liu, C.; Cheng, H. M. Adv. Mater. 2009, 21, 1756-1760. 